\title{
LIQUID OXYGEN LIQUID ACQUISITION DEVICE BUBBLE POINT TESTS WITH HIGH PRESSURE LOX AT ELEVATED TEMPERATURES
}

J. M. Jurns

J.W. Hartwig

ASRC Aerospace Corp.

Cleveland, $\mathrm{OH}, 44135$, USA

Corresponding author: John M. Jurns

ASRC Aerospace Corp.

NASA Glenn Research Center, M.S. 500-ASRC

21000 Brookpark Rd

Cleveland, $\mathrm{OH} 44135$

John.M.Jurns@nasa.gov

00.1.216.977.7416

\begin{abstract}
When transferring propellant in space, it is most efficient to transfer single phase liquid from a propellant tank to an engine. In earth's gravity field or under acceleration, propellant transfer is fairly simple. However, in low gravity, withdrawing single-phase fluid becomes a challenge. A variety of propellant management devices (PMD) are used to ensure single-phase flow. One type of PMD, a liquid acquisition device (LAD) takes advantage of capillary flow and surface tension to acquire liquid. The present work reports on testing with liquid oxygen (LOX) at elevated pressures (and thus temperatures) (maximum pressure $1724 \mathrm{kPa}$ and maximum temperature $122 \mathrm{~K}$ ) as part of NASA's continuing cryogenic LAD development program. These tests evaluate LAD performance for LOX stored in higher pressure vessels that may be used in propellant systems using pressure fed engines. Test data shows a significant drop in LAD bubble point values at higher liquid temperatures, consistent with lower liquid surface tension at those temperatures. Test data also indicates that there are no first order effects of helium solubility in LOX on LAD bubble point prediction. Test results here extend the range of data for LOX fluid conditions, and provide insight into factors affecting predicting LAD bubble point pressures.
\end{abstract}

\subsection{NOMENCLATURE}

$\mathrm{D}_{\mathrm{p}} \quad$ Pore diameter (micron)

$\Delta \mathrm{P}_{\mathrm{BP}} \quad$ Bubble point pressure $(\mathrm{Pa})$

$\rho \quad$ Fluid density $\left(\mathrm{Kg} / \mathrm{m}^{3}\right)$

$\sigma \quad$ Surface tension $(\mathrm{N} / \mathrm{m})$

$v \quad$ Kinematic viscosity (centistoke)

$\theta_{\mathrm{c}} \quad$ Fluid contact angle (degree)

\subsection{KEYWORDS}

Cryogenic fluid management, liquid oxygen 


\subsection{INTRODUCTION}

Gravity affects many fluidic processes, such as the separation of liquid and vapor within a tank: the liquid (heavier fluid) settles to the bottom while the vapor (lighter fluid) rises to the top. In the reduced gravity of a space environment, surface tension becomes a controlling mechanism for this liquid/vapor separation in a tank as the liquid and vapor tend to the state of lowest potential energy. For "wetting" systems, the liquid tends to wrap the walls or interior structures within the tank often resulting in no or very little vapor contact with the walls and these structures.

When transferring propellant in space, it is necessary to transfer single phase liquid from a propellant tank to an engine to ensure efficient thermal conditioning of the engine and safe operation after ignition. In Earth's gravity field or under acceleration during "significant" thrusting, propellant transfer is fairly simple. Single-phase fluid is transferred by opening a valve at the bottom of the propellant tank and installing an anti-vortex baffle over the tank outlet to prevent vapor and gas ingestion into the outlet. In low gravity where liquid does not sufficiently cover the tank outlet, withdrawing single-phase liquid becomes a challenge. A variety of propellant management devices (PMD) are required to ensure single-phase flow, depending on the gravitational environment. One type of PMD, a liquid acquisition device (LAD) uses capillary flow and surface tension for acquiring liquid.

Trade studies were conducted to evaluate the feasibility of utilizing liquid oxygen/liquid methane $\left(\mathrm{LOX} / \mathrm{LCH}_{4}\right)$ propellant for propulsion systems using high pressure (up to 2,400 $\mathrm{kPa}$ ) propellant tanks to feed the engine. To date, cryogenic LAD testing has not been performed at these higher pressures, and there is a question of whether or not helium pressurant solubility in the cryogenic propellants impacts the design and operation of LADs. Tests described in this report were performed to address these questions.

LADs are designed and manufactured in a variety of sizes and geometries. Multiple types of LADs are often required to achieve sufficient vapor free liquid, especially in microgravity. One type of LAD is a screen channel device. Screen channel devices closely follow the contour of the propellant tank wall and can vary in cross-section (typically a triangular or rectangular cross section). The channel side that faces the tank wall has multiple openings that are covered with tightly woven screen. As liquid is withdrawn from the tank, surface tension forces within the screen weave create a barrier to vapor entrance into the channel but allow liquid to flow freely. Liquid is wicked into the screen pores and prevents the screen from drying out if it comes into contact with vapor. If the screen dries out, vapor is admitted into the channel.

"Bubble point" is defined as the differential pressure across the screen that overcomes the surface tension of the liquid on the screen. Mathematically, bubble point is expressed as [1]:

$$
\Delta P_{B P}=\frac{4 \sigma \cos \theta_{c}}{D_{p}}
$$

The geometry of the pore and the fluid surface tension determine the bubble point of the screen. A high bubble point (fine screen mesh) is desirable to ensure single phase (liquid) fluid delivery 
and good wicking of liquid into the screen pores. Fine mesh screens, however, tend to generate a large pressure loss during outflow through the screen. The total pressure loss in the system must be less than the bubble point pressure to prevent vapor ingestion into a LAD channel.

Capillary flow LADs have been well characterized for storable propellants (propellants that are liquids at room temperature) for in-space propulsion needs [2]. The choice of screen for the LAD channel is governed by pore size and geometry, which is usually expressed as the screen weave. The screen weave refers to the number of wires per inch in each direction and the weave pattern, or the specific over/under pattern used during the screen manufacture. The screen weave is an important parameter affecting the choice of screen since certain weaves of wires are capable of producing much finer pore sizes than other weaves. As can be seen from equation (1), the geometry (size) of the hole and the surface tension of the fluid trapped within the screen determine the bubble point of the screen.

For hazardous storable propellants, such as nitrous tetroxide and monomethyl hydrazine (MMH), bubble points are typically determined experimentally using isopropyl alcohol (IPA) as a reference fluid to determine the screen pore diameter, and calculating the bubble point using known surface tension values for these propellants. Safety and environmental concerns over the use of storable propellants have led to the examination of non-toxic cryogenic propellants for onorbit propulsion for the human and robotic exploration of the Moon and Mars. Developing LAD technology for cryogenic propulsion systems and depots is enabling technology for the efficient transfer of cryogenic fluids in a low gravity environment. The use of cryogenic fluids in on-orbit propulsion systems offers the advantages of higher performance. The development of the technology must be capable of providing vapor free liquid despite the continuously changing conditions in a cryogenic propellant tank including pressurization gases, liquid saturation conditions, vapor entrapment, tank pressure control/venting, and heat transfer.

Previous experimental test programs conducted at Glenn Research Center and Marshall Space Flight Center have collected LAD data for liquid nitrogen $\left(\mathrm{LN}_{2}\right)$ [3], liquid hydrogen $\left(\mathrm{LH}_{2}\right)$ [3], LOX [4,5], and $\mathrm{LCH}_{4}[6,7]$ at saturated liquid conditions. The effects of subcooling on LAD performance were addressed at low pressure [5] Additional testing in LOX described herein continues to advance understanding of LADs.

\subsection{TEST OBJECTIVES}

The purpose of this experimental program was to collect additional bubble point data for a screen channel LAD by performing bubble point tests in LOX. There were three proposed objectives for this test effort:

1. Ascertain whether helium dissolution into liquid oxygen at pressures up to $1724 \mathrm{kPa}(250$ psia) significantly altered the relevant liquid oxygen properties, namely liquid oxygen surface tension, and therefore the predicted LAD bubble point pressure.

2. Verify liquid oxygen surface tension at temperatures from 90 to $122 \mathrm{~K}$.

3. Assess the effect of liquid viscosity on bubble point over a broader range of test conditions than prior work.

These are discussed in detail below: 


\subsection{Helium Dissolution}

Henry's Law is used to describe the relationship between the concentration of a dissolved gas in a liquid with the pressure of the fluid and is usually expressed as

$$
c=f(P, T)
$$

For gaseous helium (GHe) in liquid oxygen, this has been measured by Sinor and Kurata [8]

Table 1: Liquid Composition, Mole \% Helium

\begin{tabular}{|l|l|l|l|l|l|}
\hline $\begin{array}{l}\text { Pressure } \\
\mathrm{MPa}(\mathrm{psia})\end{array}$ & $\begin{array}{c}143 \mathrm{~K} \\
\left(258^{\circ} \mathrm{R}\right)\end{array}$ & $\begin{array}{c}128 \mathrm{~K} \\
\left(231^{\circ} \mathrm{R}\right)\end{array}$ & $\begin{array}{c}113 \mathrm{~K} \\
\left(204^{\circ} \mathrm{R}\right)\end{array}$ & $\begin{array}{c}93 \mathrm{~K} \\
\left(168^{\circ} \mathrm{R}\right)\end{array}$ & $\begin{array}{c}77 \mathrm{~K} \\
\left(139^{\circ} \mathrm{R}\right)\end{array}$ \\
\hline $1.72(250)$ & & & 0.27 & 0.14 & 0.04 \\
\hline $3.45(500)$ & & 0.86 & 0.74 & 0.33 & 0.14 \\
\hline $5.17(750)$ & 1.80 & 1.59 & 1.13 & 0.53 & 0.20 \\
\hline $6.89(1000)$ & 3.30 & 2.37 & 1.54 & 0.68 & 0.25 \\
\hline $8.62(1250)$ & 4.61 & 3.14 & 1.95 & 0.83 & 0.32 \\
\hline $10.3(1500)$ & 5.98 & 3.84 & 2.32 & 0.99 & 0.36 \\
\hline $11.9(1750)$ & 7.26 & 4.46 & 2.67 & 1.14 & 0.43 \\
\hline $13.8(2000)$ & 8.60 & 5.08 & 3.02 & 1.27 & 0.48 \\
\hline
\end{tabular}

Even though the proposed operating conditions for higher pressure fed engines are not likely to exceed $2.24 \mathrm{MPa}$ (325 psia), there is still a significant amount of helium that can be dissolved into the liquid oxygen. While there is no data suggesting that the properties of the liquid oxygen will be significantly altered by this dissolved helium content, this remains to be verified.

\subsection{Liquid Oxygen Surface Tension}

By elevating the pressure of the gaseous space above the liquid volume in a tank, it is possible to suppress boiling and evaporation, even at temperatures above the normal boiling point.

While other authors give data for surface tension up to temperatures of approximately $154 \mathrm{~K}$, the data was extrapolated for temperatures above $95 \mathrm{~K}$ based on similar calculations of liquid nitrogen. It should be noted though that using this correlation, the surface tension drops from $13.2 \mathrm{dynes} / \mathrm{cm}$ at the normal boiling point of $101.3 \mathrm{kPa}$ (one atmosphere) and $91 \mathrm{~K}$ to about 4 dynes/cm at the boiling point at $1724 \mathrm{kPa}$ (250 psia) and 130K [9]. Thus, while there is some confidence that the predicted values of surface tensions at elevated bulk liquid temperatures are known, there has been no experimental verification of those values.

\section{$\underline{4.3 \text { Liquid Viscosity Effect }}$}

Jurns et al [6] had previously proposed using a normalized kinematic viscosity correction term for calculating bubble point pressure as follows:

$$
\Delta P_{B P}=\frac{4 \sigma \cos \theta_{c}}{D_{P}}\left(\frac{v}{v_{N P B}}\right)^{1 / 3}
$$


Previous tests had indicated inconclusive results regarding the suitability of this term [7]. However, the range of fluid conditions for the tests described herein was much broader than previous experiments. The suitability of this viscosity correction term should be re-evaluated in the light of this broader range of fluid conditions.

\subsection{TEST PROGRAM}

\section{$\underline{5.1 \text { Description of Experiment }}$}

The experiment was conducted at GRC Creek Road Cryogenic Complex - Cryogenic Component Lab 7 (CCL-7) [10]. New research hardware was developed for this test program, and additional facility changes to accommodate the high pressure testing included the following:

- Fabrication of a new 0.6 liter volume high pressure LAD test tank

- High pressure supply system for gaseous helium and oxygen

- High pressure, high accuracy helium pressure controller

- High pressure piping for the new LAD test tank

A simplified schematic diagram of the test is shown in Figure 1.

Portable LOX supply dewars (450 liter capacity) were filled off-site and transported to CCL-7. A flexible line supplied LOX to the high pressure research test tank containing the LAD test hardware located inside the existing test facility research dewar. After LOX has been fed into the research test tank, it was isolated from the LOX supply. The test tank was then pressurized using the high pressure helium system. After testing, the test tank was vented and LOX drained and routed to a flash tank located immediately outside the test building.

Visual observation of test hardware inside the research dewar was extremely important for this test program. LAD screen bubble breakthrough was observed visually and correlated to the recorded differential screen pressure signal to determine the bubble point. Therefore, the new high pressure LAD test tank was supplied with ports to view the test hardware, and the facility had a live video feed to observe the LAD screen remotely during testing. The camera system was mounted between the CCL-7 dewar and high pressure test tank to view the LAD screen through a sight glass in the test tank. The video was recorded and time synchronized with the data system to aid in post-test data analysis.

\subsection{Bubble Point Tests}

For bubble point testing, the high pressure LAD test tank previously referenced is a $15.24 \mathrm{~cm}$ diameter vessel located inside the $0.23 \mathrm{~m}^{3}$ volume CCL-7 dewar as shown in Figure 2. A LAD screen sample was affixed to a mounting fixture inside the test tank. Two size LAD screens were evaluated: a $325 \times 2300$ mesh screen with a $\mathrm{D}_{\mathrm{p}}=14.4 \mu(0.000567 \mathrm{inch})$, and a $200 \times 1400$ mesh screen with a $\mathrm{D}_{\mathrm{p}}=23.4 \mu(0.00092 \mathrm{inch})$. These pore diameter values were determined by performing IPA bubble point tests and calculating Dp using Equation (1) and IPA surface tension values. The volume above the LAD screen in the test tank was filled with LOX. The volume below the LAD screen was maintained at a slightly elevated pressure to prevent flooding of the test fixture during the filling process. When the entire screen surface is wetted, surface tension forces also aid in preventing flooding of the screen. Gaseous helium or oxygen pressure below the LAD screen was gradually ramped up in small pressure steps until gas bubbles broke through the screen surface. Pressure was incremented using a supply of regulated gas and precision 
throttling valve. Pressure across the screen surface was measured using sensitive differential pressure transducers.

Tests were performed with LOX over a range of temperatures from normal boiling point (NBP) to approximately $122 \mathrm{~K}$. For NBP tests, the LOX was transferred directly into the test dewar from the LOX supply. For pressurized LOX tests, the LOX was pressurized after the test tank had been filled. For higher temperature LOX tests, the liquid was warmed through ambient heat into the system. Tables 2 and 3 show the test matrix for the two LAD screens tested. Reported bubble breakthroughs in terms of LOX temperature and pressure are also shown graphically in Figures 3 and 4; the LOX saturation curve is also plotted for reference.

\subsection{Data Acquisition}

Data for this test program was acquired using the facility LabVIEW ${ }^{\mathrm{TM}}$ data collection system, and recorded data at nominally $2 \mathrm{~Hz}$. As mentioned previously, video data of the LAD screen was also recorded, and bubble breakthrough times correlated with recorded pressure data.

Silicon diodes were located inside the test tank to measure bulk liquid temperature, vapor temperature, and LAD screen temperature. Additional diodes were located on the outside of the test tank and on the camera.

Differential pressures were measured using high accuracy pressure transducers. Screen differential pressure was measured using $0-7.5 \mathrm{kPa}$ or $0-13.8 \mathrm{kPa}$ differential pressure transducers. Liquid head was measured using a 0-7.5 kPa differential pressure transducer.

Facility instrumentation (including dewar pressure, vent system pressure, barometric pressure) was also monitored and recorded for use in data analysis.

\subsection{Test Operating Parameters}

- LOX test tank pressure - $1723.7 \mathrm{kPa}(250 \mathrm{psia})$ maximum

- LOX temperature - 91-130 K (162-234 degree R)

- $\mathrm{GHe}$ or GOX pressurant - $2068.4 \mathrm{kPa}$ (300 psia) maximum

\section{$\underline{5.5 \text { Measured Parameters }}$}

- LOX and vapor ullage temperature - $\mathrm{K}$

- Tank pressure - $\mathrm{kPa}$

- LAD screen differential pressure - $\mathrm{Pa}$

- LOX liquid level - Pa

- Test tank wall temperatures - K

- LAD screen temperature - $\mathrm{K}$ 
Table 2 - 325 x 2300 Mesh LAD Tests

\begin{tabular}{|c|c|c|c|}
\hline Liquid & Gaseous & \multicolumn{2}{|c|}{ Fluid Test Conditions } \\
\hline Component & Component & Pressure [kPa] & Temperature [K] \\
\hline LOX & GHe & $344.7-689.5$ & $105.5-108.3$ \\
\hline LOX & GHe & $689.5-1034.2$ & $108.3-113.9$ \\
\hline LOX & GHe & $1034.2-1379.0$ & $113.9-116.7$ \\
\hline LOX & GHe & $1379.0-1723.7$ & $113.9-120$ \\
\hline LOX & GHe & $193.1-689.5$ & $100-105.5$ \\
\hline LOX & GHe & $689.5-1034.2$ & $105.5-106.7$ \\
\hline LOX & GHe & $1034.2-1379.0$ & $105.5-108.9$ \\
\hline LOX & GHe & $1379.0-1723.7$ & 110.6 \\
\hline LOX & GOX & 1500 & 92.2 \\
\hline LOX & GHe & 137.9 & 94.4 \\
\hline LOX & GHe & $137.9-344.7$ & 97.2 \\
\hline LOX & GHe & $572.3-861.8$ & 100 \\
\hline LOX & GHe & $882.5-1551.3$ & $105.5-108.3$ \\
\hline LOX & GHe & $1585.8-1723.7$ & $111.1-113.9$ \\
\hline LOX & GHe & $517.1-1034.2$ & $125-130.6$ \\
\hline LOX & GHe & $1034.2-1379.0$ & $118.3-128.3$ \\
\hline LOX & GHe & $1379.0-1723.7$ & $92.2-95$ \\
\hline LOX & GOX & $1379.0-1723.7$ & $94.4-105.5$ \\
\hline LOX & GOX & $131-344.7$ & $100-113.9$ \\
\hline LOX & GOX & $344.7-689.5$ & $113.3,117.8-122.2$ \\
\hline LOX & GOX & $689.5-1034.2$ & \\
\hline LOX & GOX & $1034.2-1379.0$ & $105.6-108.9,113.3-119.4$ \\
\hline LOX & GOX & $1379.0-1723.7$ & \\
\hline
\end{tabular}

Table 3 - 200 x 1400 Mesh LAD Tests

\begin{tabular}{|c|c|c|c|}
\hline Liquid & Gaseous & \multicolumn{2}{|c|}{ Fluid Test Conditions } \\
\hline Component & Component & Pressure [kPa] & Temperature [K] \\
\hline LOX & GHe & $676.5-951.4$ & $109-113.7$ \\
\hline LOX & GHe & $941.9-980.4$ & $116.3-116.5$ \\
\hline LOX & GHe & $1307.2-1347.6$ & $105.7-119.5$ \\
\hline LOX & GHe & $415-532$ & $105.7-108.7$ \\
\hline LOX & GHe & $213.2-290.3$ & $97.8-101.2$ \\
\hline LOX & GHe & $746.8-1221.2$ & $103.3-112.2$ \\
\hline LOX & GHe & $1598.4-1717.4$ & $112.1-120.3$ \\
\hline LOX & GHe & $137.4-171.9$ & $93-95.5$ \\
\hline LOX & GHe & $303.8-558.2$ & $97.2-106$ \\
\hline LOX & GHe & $693.5-851.8$ & $106-108.6$ \\
\hline LOX & GHe & $1052.7-1159$ & $108.7-111.1$ \\
\hline LOX & GHe & $1359.4-1421.1$ & $112.2-112.5$ \\
\hline LOX & GHe & $1607.9-1744.2$ & $113.2-114.7$ \\
\hline LOX & GHe & $1239.1-1765.4$ & $114.3-122.6$ \\
\hline LOX & GHe & $203.1-586.2$ & $95.8-106.5$ \\
\hline
\end{tabular}




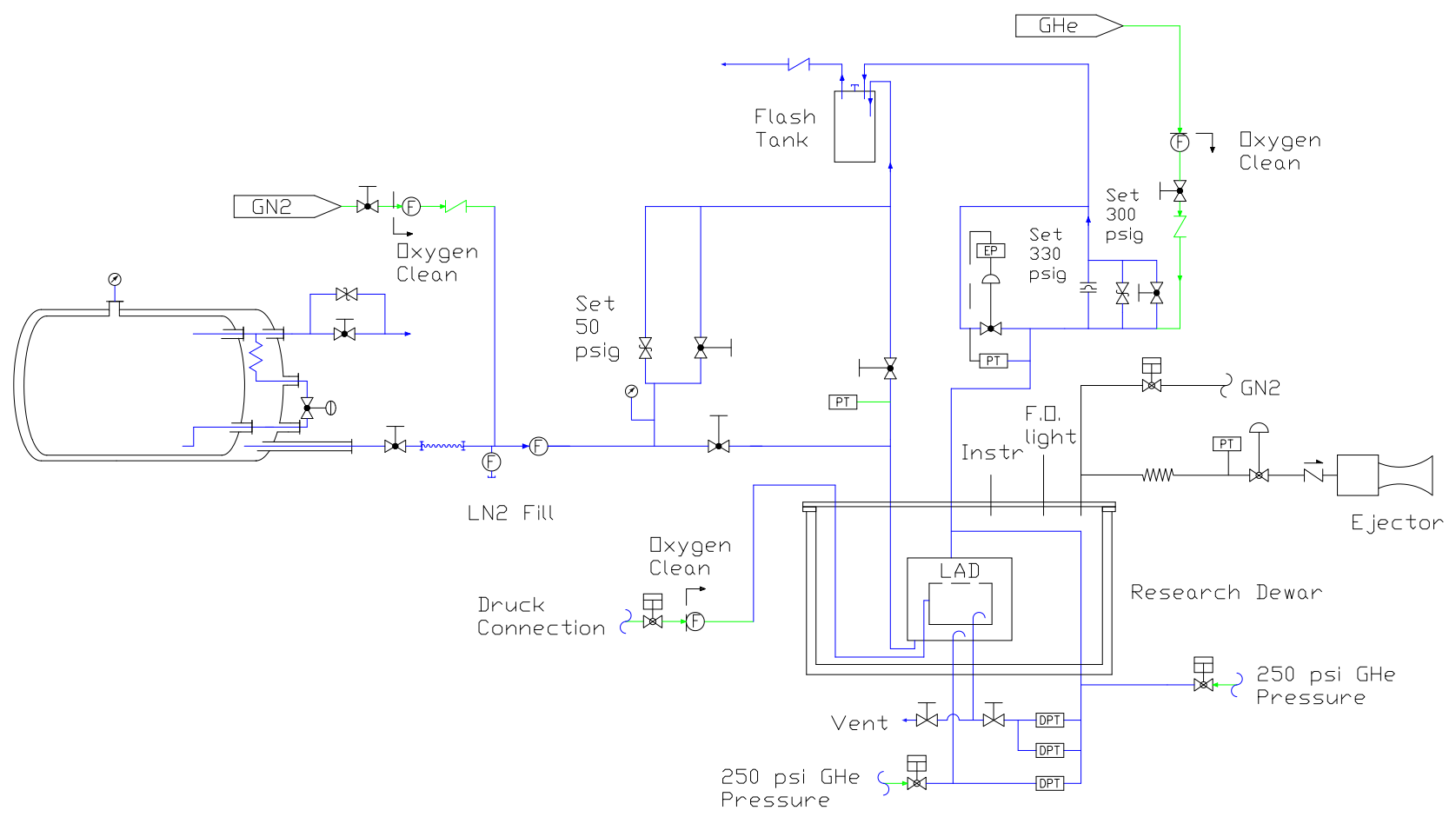

Figure 1 - Simplified System Schematic Diagram

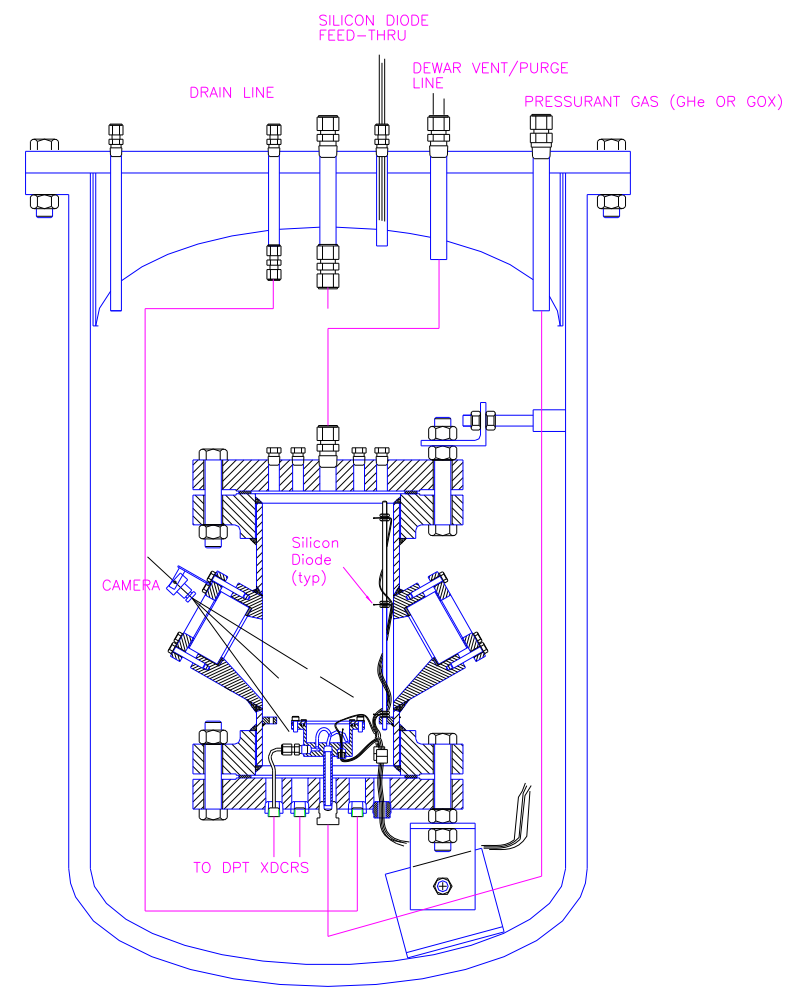

Figure 2 - Bubble Point Test Tank inside CCL-7 Receiver Dewar 


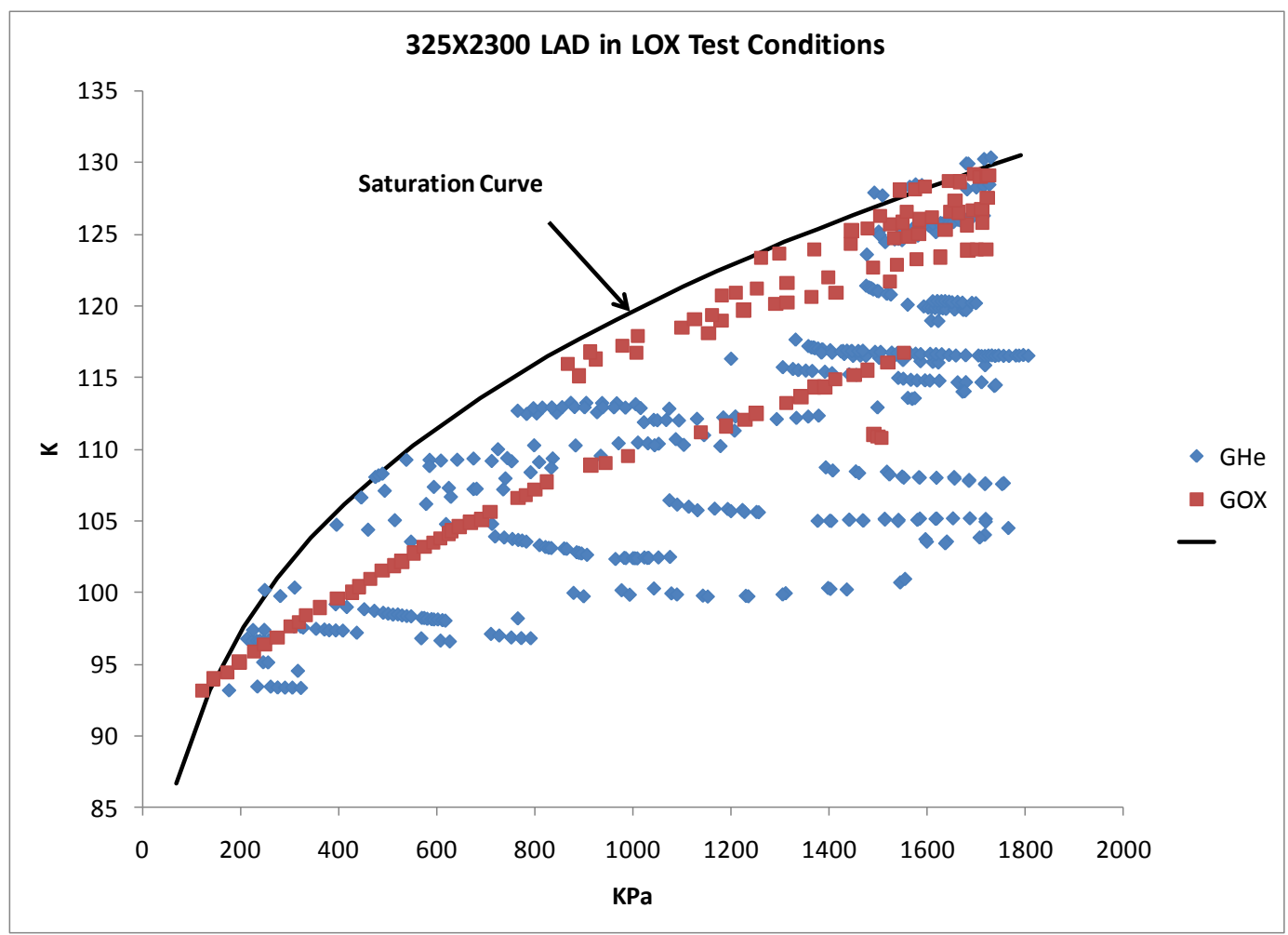

Figure 3

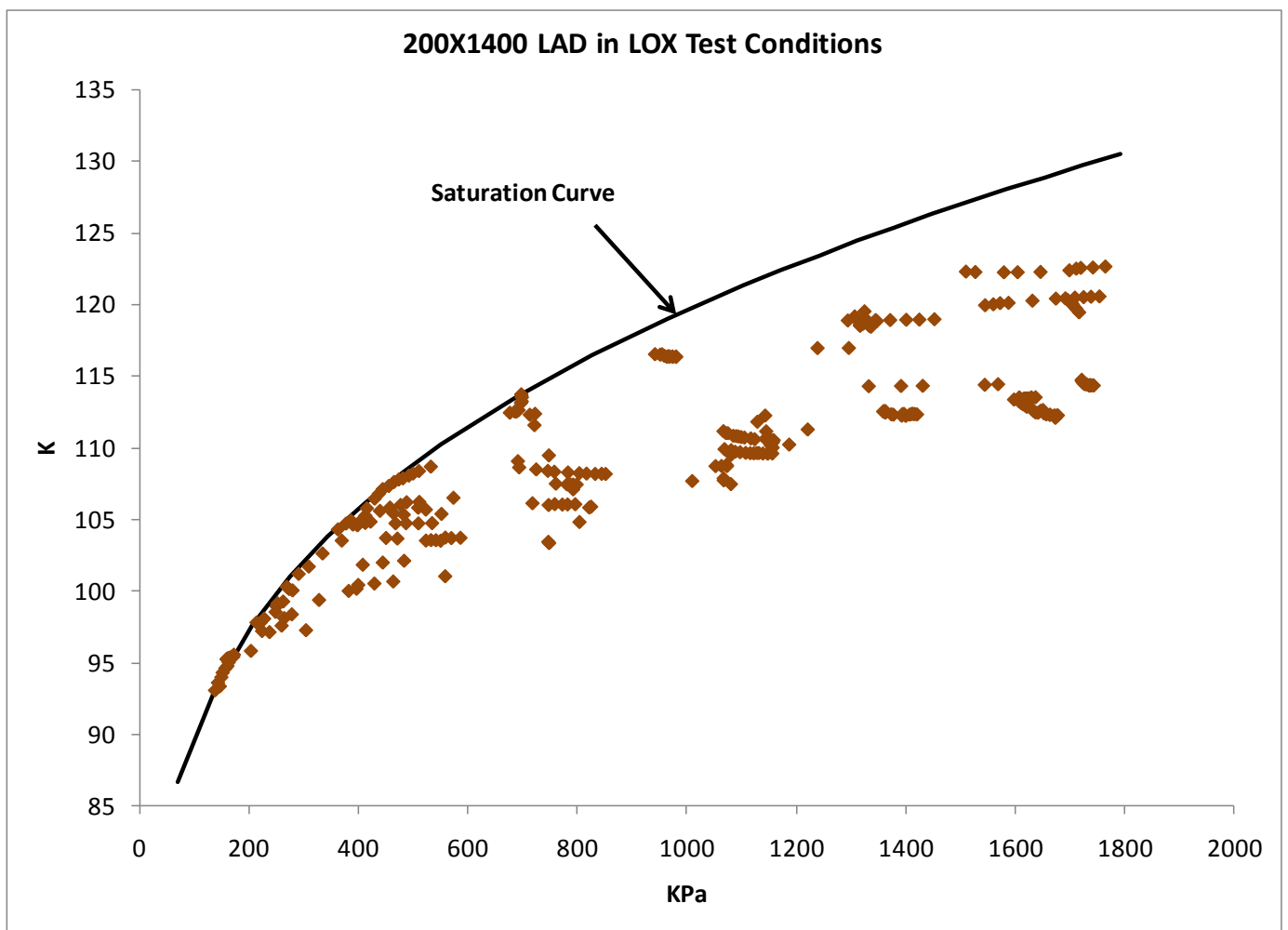

Figure 4 


\subsection{RESULTS}

\subsection{Bubble Point Predictions}

Two LAD screens were tested:

- $325 \times 2300$ mesh

- 200x1400 mesh

The 200x1400 mesh LAD was tested with LOX using GHe as the pressurant gas. The $325 \times 2300$ mesh LAD was tested with LOX using both GHe and GOX as pressurant gases. GOX pressurant testing was included to provide baseline data to compare with GHe pressurant test results.

\subsubsection{5x2300 LAD}

For LOX with GHe pressurant tests, bubble point data was plotted as a function of bulk liquid temperature, noting that surface tension is a strong function of saturation temperature. Figure 5 shows test data and the predicted bubble point based on Equation (1). Note Equation (1) under predicts the data, slightly more so at lower fluid temperatures. As liquid temperature increases, predicted value and test data agree more.

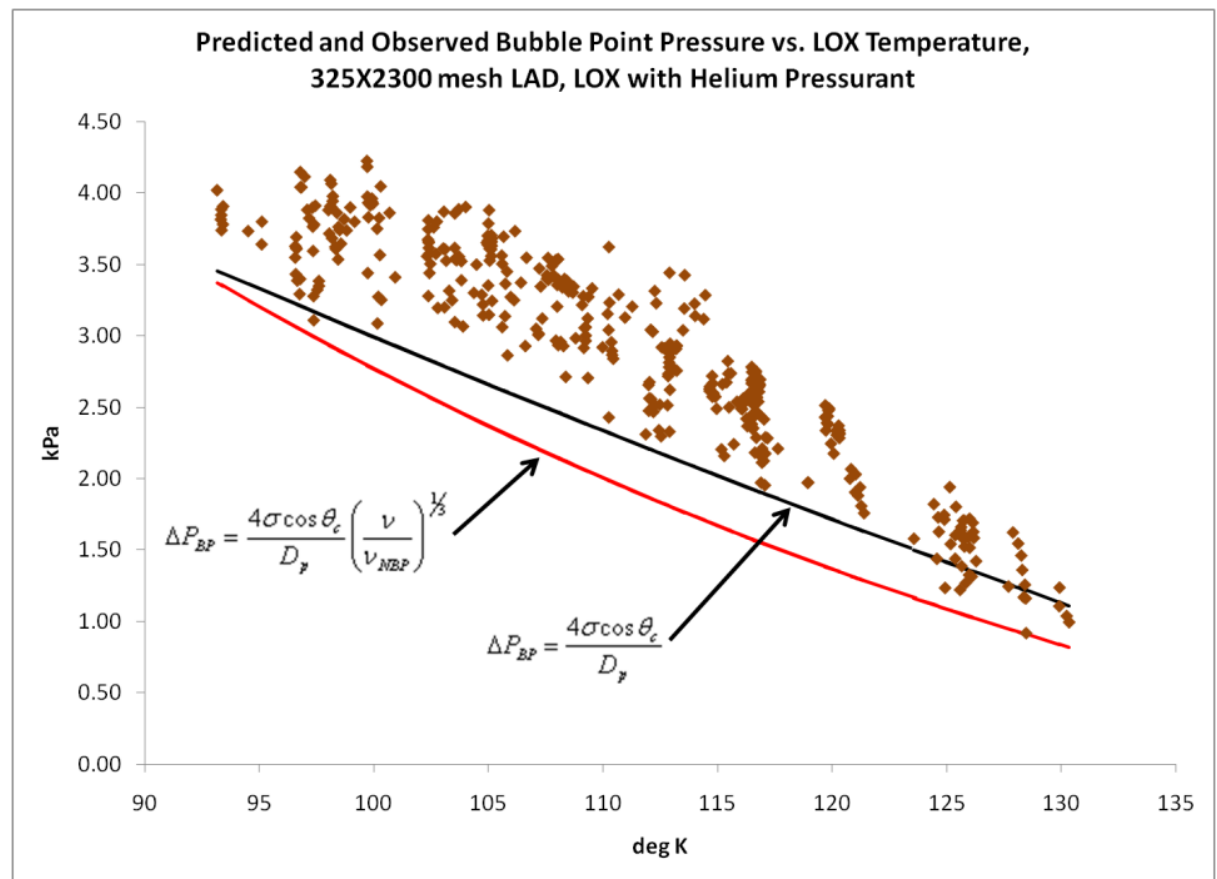

Figure 5

Comparing data and predicted bubble points using the viscosity correction term from Equation (3) [6], it appears that the correction provides a slightly better correlation to the data, but with predicted bubble points still under-predicting the data. Jurns [5], and Meserole \& Jones [11] both noted that for $\mathrm{LOX}$ and $\mathrm{LH}_{2}$ using helium as a pressurant, bubble point data was typically higher than predicted values. This was likely due to higher surface tension values based on lower liquid temperature at the liquid/vapor (L/V) interface. A lower temperature at the L/V interface would result from the requirement that the liquid temperature at the interface must be the equilibrium temperature for the partial pressure of oxygen at the interface. Silicon diode temperatures at the LAD screen indicated that indeed the L/V interface temperature was lower 
than that of the bulk liquid by approximately $3 \mathrm{~K}$, as shown in Figure 6 for a typical test using GHe pressurant. By comparison, for LOX tests using GOX as a pressurant, L/V interface temperatures were typically very close to the saturation temperature based on test tank pressure, as shown in Figure 7.

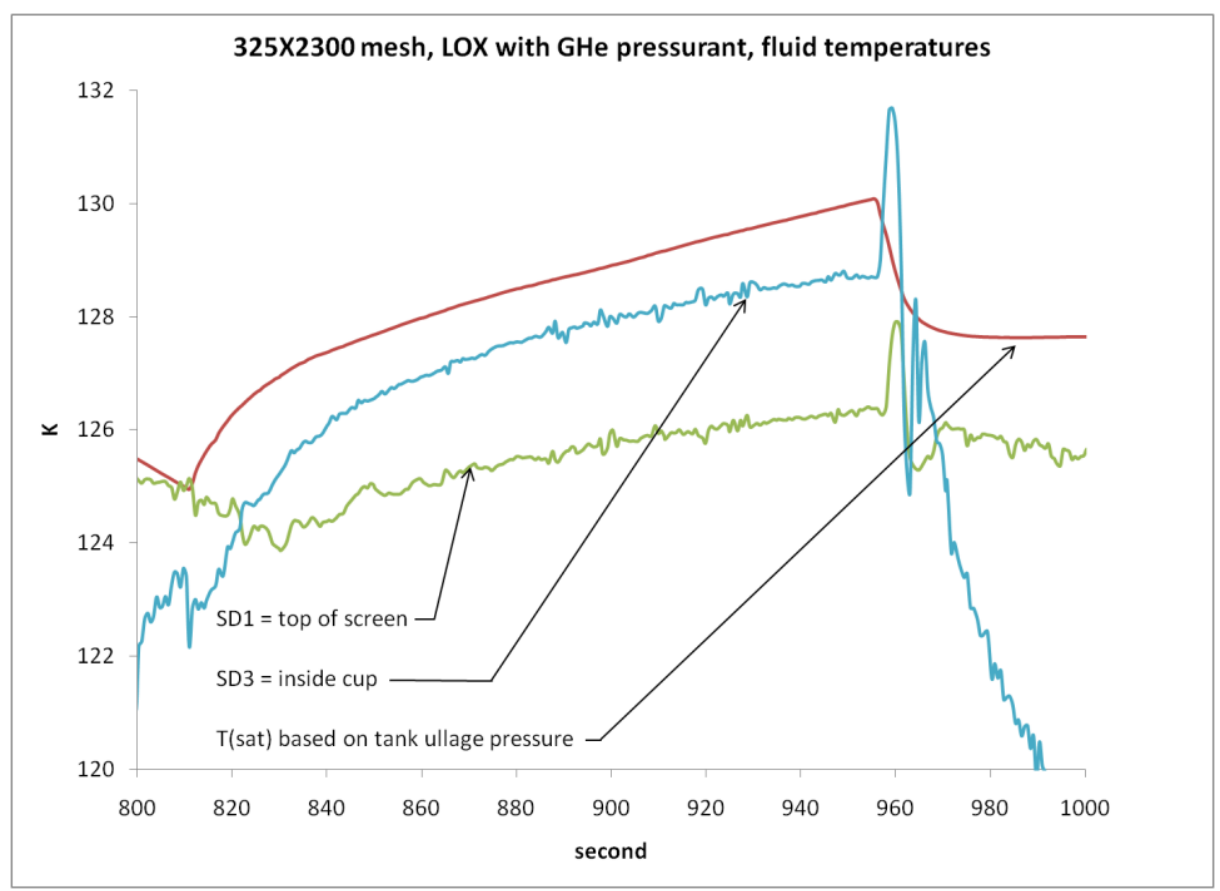

Figure 6 - LOX temperatures using GHe to determine bubble point

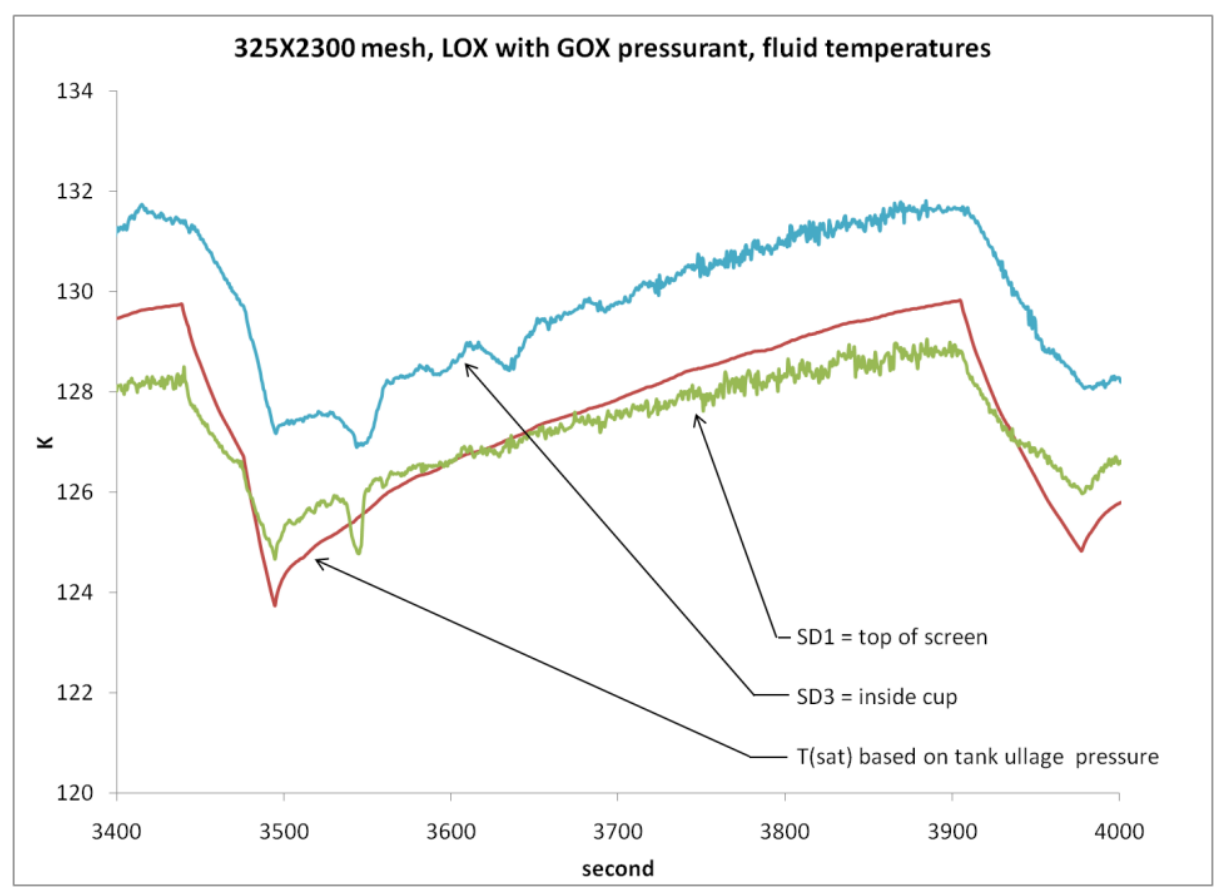

Figure 7 - LOX temperatures using GOX to determine bubble point 
For subcooled LOX using GHe pressurant the measured temperature at the L/V interface was generally colder than the bulk liquid temperature. However, this may not necessarily be used to accurately determine the actual $\mathrm{L} / \mathrm{V}$ interface temperature. Heat transfer from the bulk liquid to the screen would likely bias this measurement. One way to accurately determine the L/V interface temperature is to look up the saturation temperature of liquid based on the partial pressure of oxygen at the interface. However, for these tests, the partial pressure of oxygen at the interface was not directly measured. The observed lower temperature measured at the screen does give an indication of a lower oxygen partial pressure, which would result in higher surface tension values at the $\mathrm{L} / \mathrm{V}$ interface, tending to shift the predicted bubble point up more towards the observed data.

Bubble point tests were also performed using GOX as the pressurant. For these tests, predicted values and test data correlated better, with predictions being slightly greater than test data. However, with corrected predictions using Equation (3), there was good agreement between data to the corrected predictions (refer to Figure 8). No correction for L/V interface temperature was required, as it was previously noted that interface temperatures were very close to the saturated temperature of the bulk liquid.

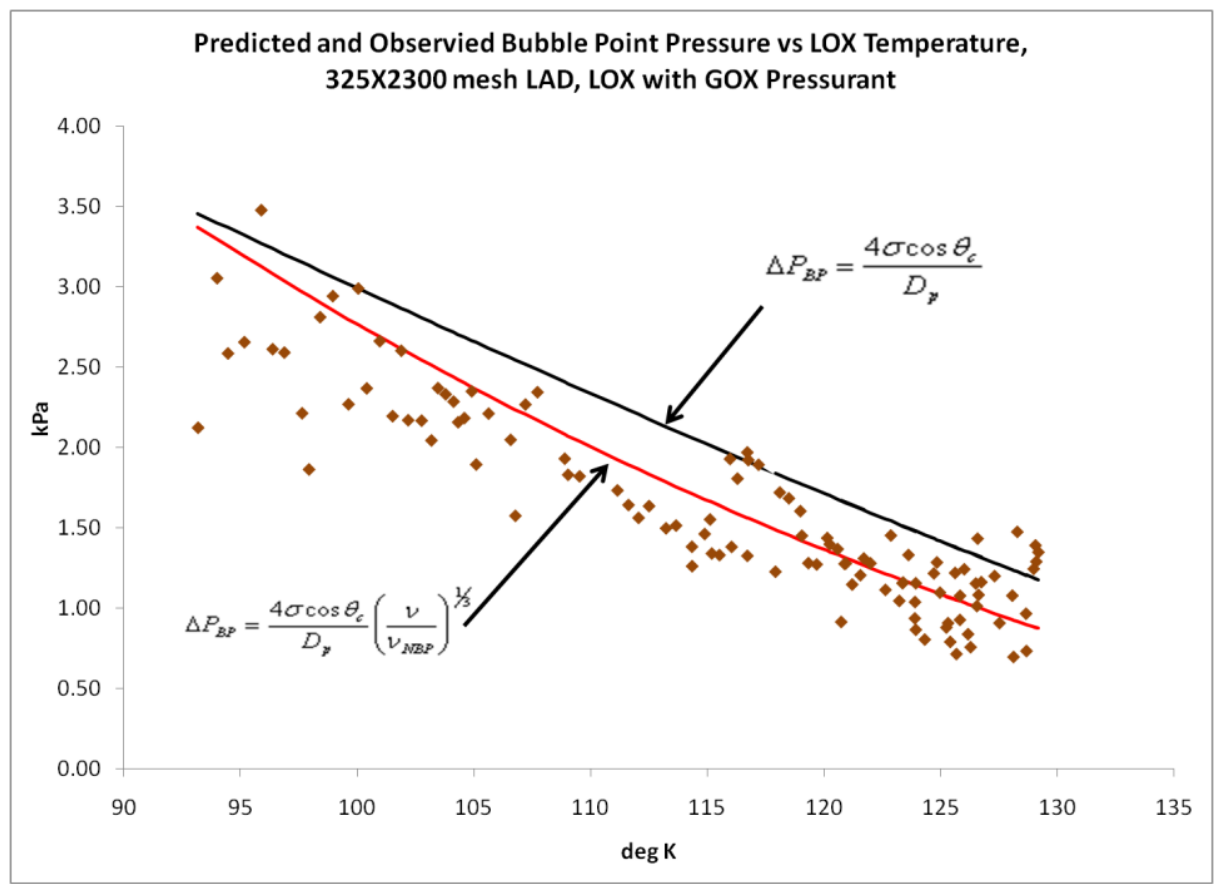

Figure 8

\subsubsection{0x1400 LAD}

For LOX with GHe pressurant, bubble point data was plotted as a function of bulk liquid temperature in the same manner as the $325 \times 2300$ LAD data. As with the $325 \times 2300$ mesh LAD, the prediction based on bulk liquid temperature under predicts the test data as shown in Figure 9. It is noted that comparing the $325 \times 2300$ screen with the $200 \times 1400$ screen; for LOX at similar conditions, the data correlates well with screen pore diameter. Again, as with the $325 \times 2300$ screen using GHe pressurant, a lower oxygen partial pressure would result in higher viscosity values, effectively shifting the predicted values up closer to observed data. 


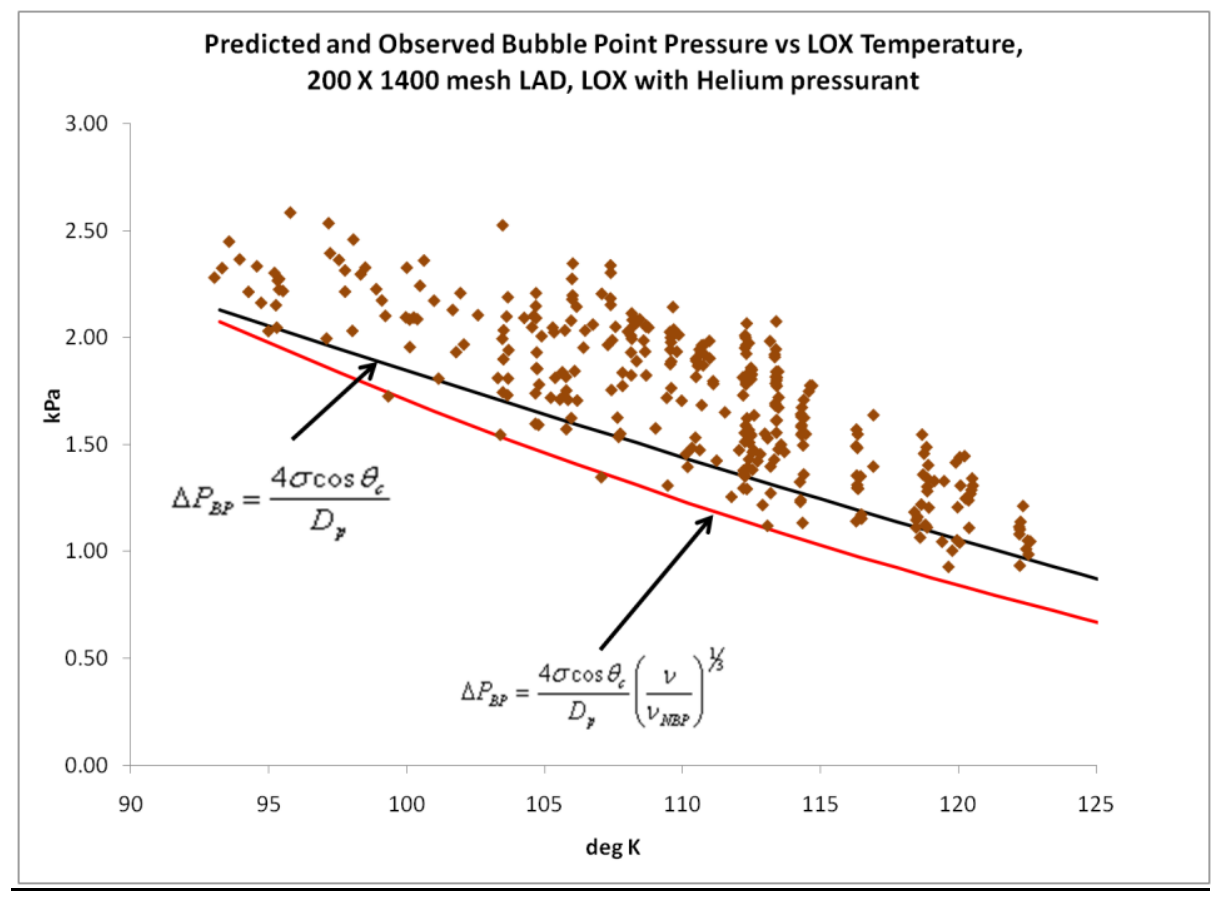

Figure 9

\subsection{Helium Solubility}

Test data was also analyzed to evaluate whether helium dissolving in the LOX had any appreciable effect on LOX surface tension values. To determine if helium dissolution had any effect, we examined several tests where the pressure was maintained above $1300 \mathrm{kPa}$ for at least one hour, and GHe was used as the pressurant gas on the LAD, with liquid held at constant temperature and pressure.

Zimmerli [12] discussed equilibration times and diffusion rates for helium in cryogens. Equilibration time was based on straight diffusion of the solute (helium) into the solvent (cryogenic liquid), and assumed no mixing. Although there is sparse data on the diffusivity rates of helium into cryogens, some data does exist for diffusivity of helium into liquid methane [13]. Based on Zimmerli's report, it would take nearly 6 hours for helium to reach half its equilibrium concentration in liquid methane at a depth of $1 \mathrm{~cm}$. Tests reported herein were on the order of several hours, and the liquid was thoroughly mixed by constant bubbling of helium through the oxygen. Therefore, if diffusivity rates were similar for helium in LOX to helium in liquid methane, it would be reasonable to assume that the amount of helium dissolved in the LOX was a noticeable fraction of its maximum solubility. That being the case, if there were an effect on surface tension, it should be evident in the data.

Several data sets that met this criteria were examined. One typical data set is shown in Figure 10. From the data examined, there was no conclusive evidence that the presence of helium had any first order effect on bubble point values. 


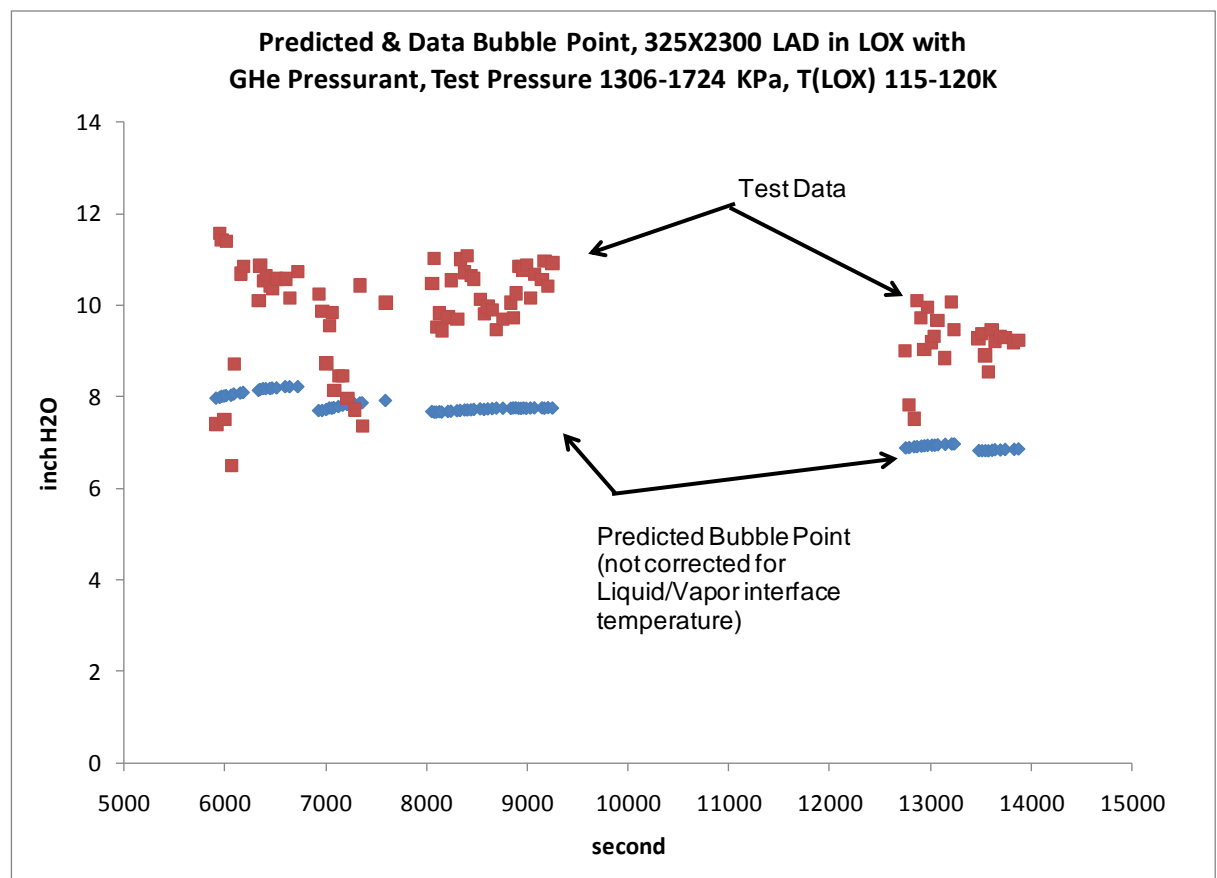

Figure 10

\subsection{Liquid Oxygen Surface Tension}

It was previously noted that there is published LOX surface tension values for temperatures up to approximately $154 \mathrm{~K}$, and that the data is extrapolated for temperatures above $95 \mathrm{~K}$. This test program evaluated bubble point data for LOX with temperatures ranging from $92-130 \mathrm{~K}$.

Using the published surface tension values, and correcting for $\mathrm{L} / \mathrm{V}$ interface temperatures, bubble point data agreed well predictions. Although there was scatter in the data, one could draw the conclusion that published LOX surface tension values are consistent with this data for temperatures as high as $130 \mathrm{~K}$ based on this experimental data.

\subsection{DISCUSSION/CONCLUSIONS}

LAD bubble point tests were performed in LOX for two LAD screens - 200x 1400 and 325x2300 mesh screens. The bubble point pressure was determined in LOX at liquid pressures up to 1724 $\mathrm{kPa}$, and liquid temperatures as high as $130 \mathrm{~K}$. Experiments conducted in this study have significantly extended the range of fluid conditions for cryogenic LAD testing. There are some general observations that can be made from these tests that are of interest to designers.

1. Tests have verified a significant drop in bubble point pressure in LOX at higher temperatures. This observation was consistent with calculations based on available LOX surface tension values in the literature. However, the significant issue that arises from this fact is that as designers consider pressure fed engines using cryogenic liquid propellants, they must also consider the possibility that cryogens stored and delivered at higher pressures may have a corresponding higher fluid temperature. This higher temperature will result in significantly lower bubble point pressures for LOX, and system design must accommodate this lower bubble point, or put controls in place to maintain LOX at lower temperatures.

2. These tests have shown that using helium as a pressurant gas results in an under-prediction of bubble point values. This was attributed to lower temperatures at the liquid/vapor interface 
on the LAD screen due to the requirement that the liquid temperature be in equilibrium with the partial pressure of oxygen at the interface. The presence of helium lowers the partial pressure of oxygen, resulting in a lower temperature and higher surface tension value, effectively increasing the bubble point. Future tests may consider directly measuring the composition of the gas beneath the LAD screen to accurately determine partial pressures of helium and oxygen.

3. For autogenously pressurized LADs in LOX (gaseous oxygen pressurant), no temperature correction calculation was required, as the LOX temperature at the L/V interface was essentially the same as the saturation temperature at the system pressure.

4. Use of a normalized viscosity correction factor as shown in Equation (3) may provide an improved bubble point prediction, presuming that the surface tension at the $\mathrm{L} / \mathrm{V}$ interface can be accurately ascertained based on oxygen partial pressure. The shape of the curve more closely follows the test data than does the straight line prediction from Equation (1).

5. There does not appear to be any significant first order effects of helium solubility on LOX surface tension values. This observation is valid for test durations on the order of hours. For long term missions where there may be orders of magnitude longer time, helium solubility may be an issue. However, based on known time scales for dissolution of helium in cryogens, this is unlikely a problem.

\subsection{FUTURE WORK}

Subsequent to completion of these tests, LAD tests were conducted at the NASA Glenn Research Center using the same test hardware used for the tests reported herein. These test were conducted with liquid nitrogen and liquid methane at pressures up to $1724 \mathrm{kPa}$ (250 psia). Data analysis from these tests is currently in process.

\subsection{ACKNOWLEDGEMENTS}

This work was sponsored by the NASA Exploration Technology Development and Demonstration Program Office, and was performed under NASA Glenn Research Center contract NNC06BA07B.

\subsection{REFERENCES}

1. Blatt, M.H, et al, "Low Gravity Propellant Control Using Capillary Devices in Large Scale Cryogenic Tanks", General Dynamics Report No. GDC-DD70-006, August 1970.

2. Fester D. A. et. al. "Surface Tension Propellant Acquisition System Technology for Space Shuttle Reaction Control Tanks", AIAA 75-1196, Sept. 1975.

3. Chato D.J. and Kudlac M.T., "Screen Channel Liquid Acquisition Devices for Cryogenic Propellants", AIAA2002-3983 2002.

4. Kudlac M.T., Jurns J.M., "Screen Channel Liquid Acquisition Devices for Liquid Oxygen", $42^{\text {nd }}$ AIAA Joint Propulsion Conference, Sacramento, July 2005.

5. Jurns J.M., McQuillen J.B ., "Liquid Acquisition Device Testing with Subcooled Liquid Oxygen", $44^{\text {th }}$ AIAA Joint Propulsion Conference, Hartford, CT, July 2008

6. Jurns J.M. et al. "Bubble Point Measurements with Liquid Methane of a Screen Channel Capillary Liquid Acquisition Device", 54 th JANNAF Propulsion Meeting, Denver, CO, May 2007.

7. Jurns J.M., McQuillen J.B., "Bubble Point Measurements with Liquid Methane of a Screen Capillary Liquid Acquisition Device”, 2007 Cryogenic Engineering Conference, Chattanooga, TN, July 2007 
8. Sinor, J. E. and Kurata, F. "Solubility of Helium in Liquid Argon, Oxygen, and Carbon Monoxide," Journal of Chemical and Engineering Data, Vol. 11, No. 4, 1966

9. Roder, H. M. and Weber, L. A. "ASRDI Oxygen Technology Survey. Volume 1: Thermophysical Properties," NASA SP 3071, 1972.

10. Jurns, J.M. and Kudlac M.T., "NASA Glenn Research Center Creek Road Complex - Cryogenic Testing Facilities", Cryogenics 46, 2006, pp. 98-104.

11. Meserole, J.S., Jones, O.S., "Pressurant Effects on Cryogenic Liquid Acquisition Devices," Journal of Spacecraft and Rockets, Vol. 30, No. 2, March-April 1993

12. Zimmerli G.A., Asipauskas M., Van Dresar N.T., "Empirical Correlations for the Solubility of Pressurant Gasses in Cryogenic Propellants", Cryogenics 50, September 2010, pp. 556-560

13. Rhodes H.L., DeVaney W.E., Tully P.C., "Phase Equilibria Data for Helium-Methane in the Vapor-Liquid and Fluid-Fluid Region", Journal of Chemical and Engineering Data, Vol. 16, No. 1, 1971 


\subsection{Vitae}

John Jurns is a research engineer with ASRC Aerospace Corp., supporting cryogenic fluid systems research and development at the NASA Glenn Research Center. His career spans 33 years working in the industrial gas industry and in government R\&D. Mr. Jurns holds a B.S.C.E degree from the SUNY at Buffalo and a M.S.M.E degree from Cleveland State University. He is a member of the Cryogenic Society of America and the AIAA. Mr. Jurns' areas of expertise include cryogenic fluid mass gauging, thermodynamic vent systems, densified cryogenic propellants, Zero Boil-off (ZBO) technology, liquid acquisition devices, and cryogenic propellant systems analysis.

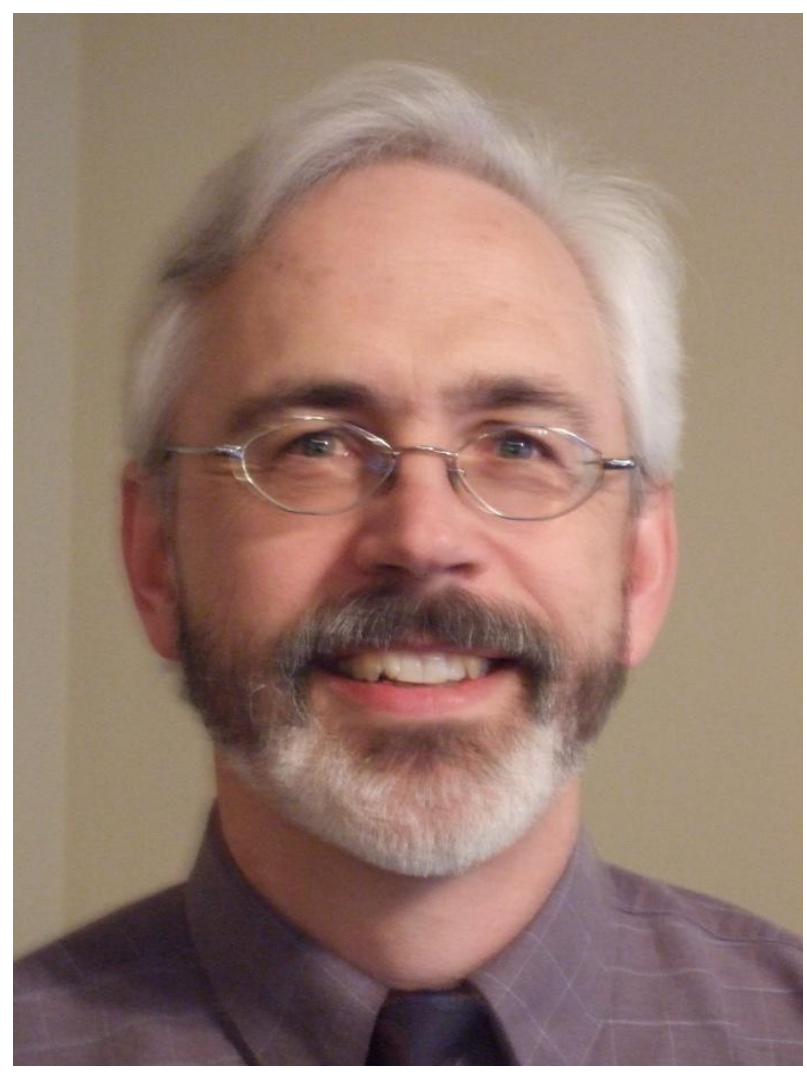


Jason Hartwig is a Research Aerospace Engineer with ASRC Aerospace Corp., supporting cryogenic fluid systems R\&D at the NASA Glenn Research Center. Jason received his B.S. in Physics, his M.S. in Aerospace Engineering under the Case Prime Fellowship, and is currently pursuing his $\mathrm{PhD}$ in Aerospace Engineering at Case Western Reserve University. Jason has 7 years experience in the areas of cryogenic engineering, laser diagnostics, combustion and propulsion. At Glenn, Jason develops technology for cryogenic fluid management systems such as multi-layer insulation, liquid acquisition devices, low-g fluid transfer, and pressurization systems. Jason develops heat leak, pressurization and fluid flow analytical models for cryogenic fluid systems.

Photo not available 